\title{
Morphometric multislice computed tomography examination of the craniovertebral junction in neck flexion and extension
}

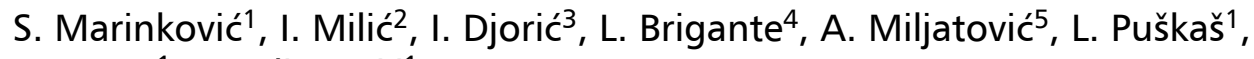 \\ S. Kapor ${ }^{1}$, J. Boljanović ${ }^{1}$ \\ ${ }^{1}$ Institute of Anatomy, Faculty of Medicine, University of Belgrade, Belgrade, Serbia \\ ${ }^{2}$ Clinic of Neurosurgery, Faculty of Medicine, University of Belgrade, Belgrade, Serbia \\ ${ }^{3}$ Department of Radiology, Faculty of Medicine, University of Belgrade, Belgrade, Serbia \\ ${ }^{4}$ Department of Neurosurgery, City Hospital, University of Salerno, Salerno, Italy \\ ${ }^{5}$ Department of Neuropsychiatry, City Hospital Zvezdara, Belgrade, Serbia
}

[Received 1 April 2016; Accepted: 18 May 2016]

Background: Detailed study of the craniovertebral junction (CVJ) is necessary to completely understand the mechanism of its flexion and extension.

Materials and methods: One cadaver head was sectioned in the sagittal plane. Also, in 22 volunteers, examined using the multislice computed tomography (MSCT), 14 parameters and 2 angles were measured in the neutral position, flexion and extension.

Results: The obtained measurements showed the anterior part of the occiput to move inferiorly in flexion, and the anterior atlas arch and the tip of the dens to get closer to the basion. At the same time, the opisthion moves superiorly, but the cervical spine bends anteriorly. Consequently, the dens-opisthion diameter and the opisthion-posterior atlas arch distance slightly decrease in length, whilst the arches of the atlas (C1), axis (C2) and C3 vertebra become more distant. Following extension, the posterior part of the occiput moves inferiorly, so that the basion-dens tip, the basion-axis arch, and the basion-posterior atlas arch distances increase in length. In contrast, the distances of the C1-C3 arches decrease in length. The angle between the foramen magnum and the dens tip decreases 1.620 on average in flexion, but increases 3.230 on average in extension. The angle between the axis body and the opisthion also decreases in flexion (mean, 3.360) and increases in extension (mean, 6.570). Among the congenital anomalies, a partial agenesis of the posterior atlas arch was revealed (4.5\%), as well as an anterior dehiscence of the $\mathrm{C} 1$ foramen transversarium (13.6\%).

Conclusions: The mentioned measurements improved our understanding of the CVJ biomechanics. The obtained data can be useful in the evaluation of the CVJ instability caused by trauma, congenital anomalies and certain spine diseases. (Folia Morphol 2017; 76, 1: 100-109)

Key words: atlas, axis, craniovertebral junction, extension, flexion, multislice computed tomography, occipital condyle

Address for correspondence: Dr. S. Marinković, Institute of Anatomy, Faculty of Medicine, University of Belgrade, Dr. Subotić 4/2, 11000 Belgrade, Serbia, tel: +381-11-2645958, fax: +381-11-2645958, e-mail: mocamarinkovic@med.bg.ac.rs 


\section{INTRODUCTION}

The craniovertebral junction (CVJ), in the narrower sense, consists of the right and left occipital condyle $(\mathrm{Oc})$, the atlas (C1) and the axis (C2) $[19,22,34]$. Flexion and extension of the cervical spine, including the CVJ, were examined in the experimental animals [9], in the post mortem human samples [2], in certain digital models [31, 37], and in healthy volunteers using the radiographs, computed tomography (CT), and the kinematic magnetic resonance imaging (MRI) method, but not the multislice CT (MSCT) $[8,12,19$, $20,22,24,31,34]$. The flexion and extension were also examined in the patients with certain degenerative diseases, tumours, or traumatic injuries of the cervical spine $[6,11,17,21]$.

We think, however, that the measurements performed in some of those studies are not sufficient for a complete understanding of what precisely occurs during the corresponding CVJ movements. Because of that, we decided to examine in detail certain parameters following flexion and extension of the CVJ. In order to do this, we applied the serial MSCT scans, as well as a three-dimensional (3D) reconstruction of the bones forming the junction, in three neck positions: neutral, flexion and extension.

\section{MATERIALS AND METHODS}

First of all, we used one anatomical specimen of the head and brain following approval of the authorities of the Institute of Anatomy and the Ethics Committee of the University Clinical Centre. The specimen was injected with a $10 \%$ formaldehyde solution and then fixed in the same solution for 6 weeks. After freezing it at $-25^{\circ} \mathrm{C}$ for 3 weeks, it was serially sectioned in the sagittal plane.

In addition, 22 healthy individuals were examined, that is, $12(55 \%)$ males, aged $33.25 \pm 7.62$ years, and $10(45 \%)$ females, aged $31.30 \pm 5.52$ years on average. The written consent of each volunteer was obtained. The examination was approved by the authorities of the Department of Radiology and the Ethics Committee of the University Clinical Centre.

The MSCT examination of the volunteers was performed in a Siemens Somatom Definition AS 128-slice scanner. Linear measurements of certain parameters were performed in tree planes (axial, coronal and sagittal) using standard software installed in the MSCT equipment. 3D reconstruction was carried out in all volunteers. We measured 14 parameters in each

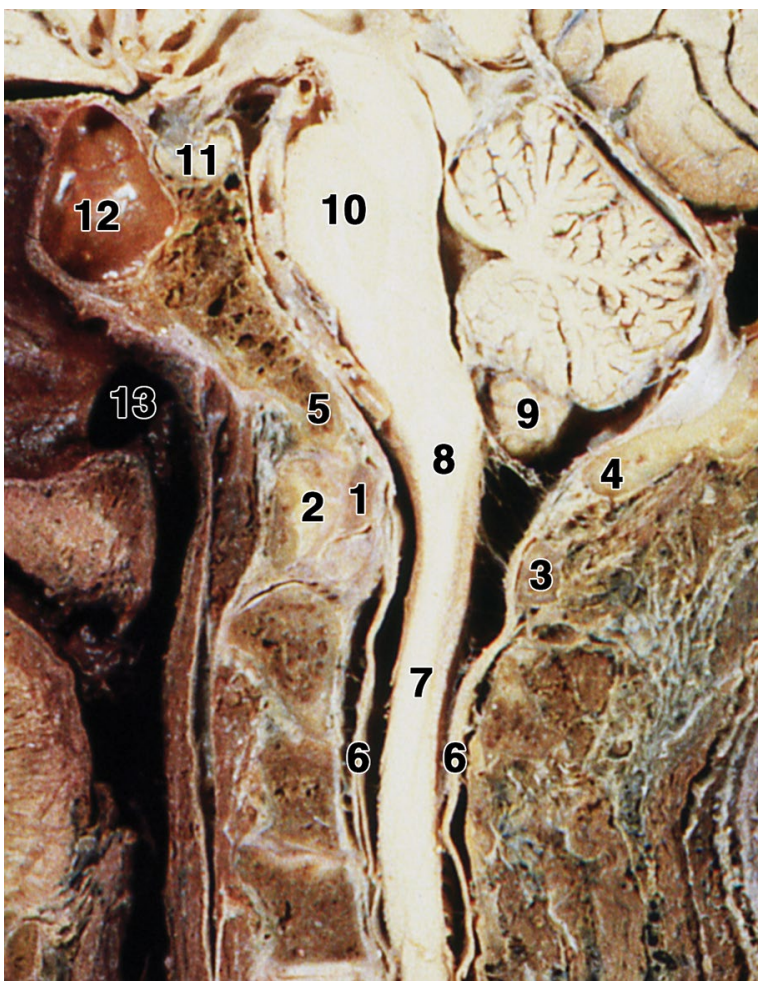

Figure 1. The sagittal and slightly oblique anatomical section of the craniovertebral junction; 1 - the odontoid process; 2 - the anterior, and 3 - the posterior arch of the atlas; 4 - the posterior edge of the foramen magnum; 5 - the anterior edge of the foramen magnum; 6 - the spinal dura; 7 - the cervical cord; 8 the medulla oblongata; 9 - the cerebellar tonsil; 10 - the pons; 11 - the pituitary gland; 12 - the sphenoid sinus; 13 - the nasopharynx.

subject, which are related to certain distances among the portions of the occiput, atlas and axis, as well as two corresponding angles. Both the parameters and the angles will be presented in the Results section.

The statistics comprised minimum and maximum values, as well as counting the mean value, standard deviation (SD), and $95 \%$ confidence interval (CI). The ANOVA test was applied as well.

\section{RESULTS}

The CVJ is a complex transition zone between the cranium and spinal column, along with the adjacent head and neck structures, and the brain stem and spinal cord junction (Fig. 1). The CVJ consists of the bony elements interconnected by certain joints, i.e. the atlanto-occipital $(\mathrm{Oc}-\mathrm{C} 1)$, the lateral atlantoaxial (C1-C2) and the median atlantoaxial joints, and surrounded by the soft tissue, the blood vessels, and the vital neural structures (Fig. 1). 

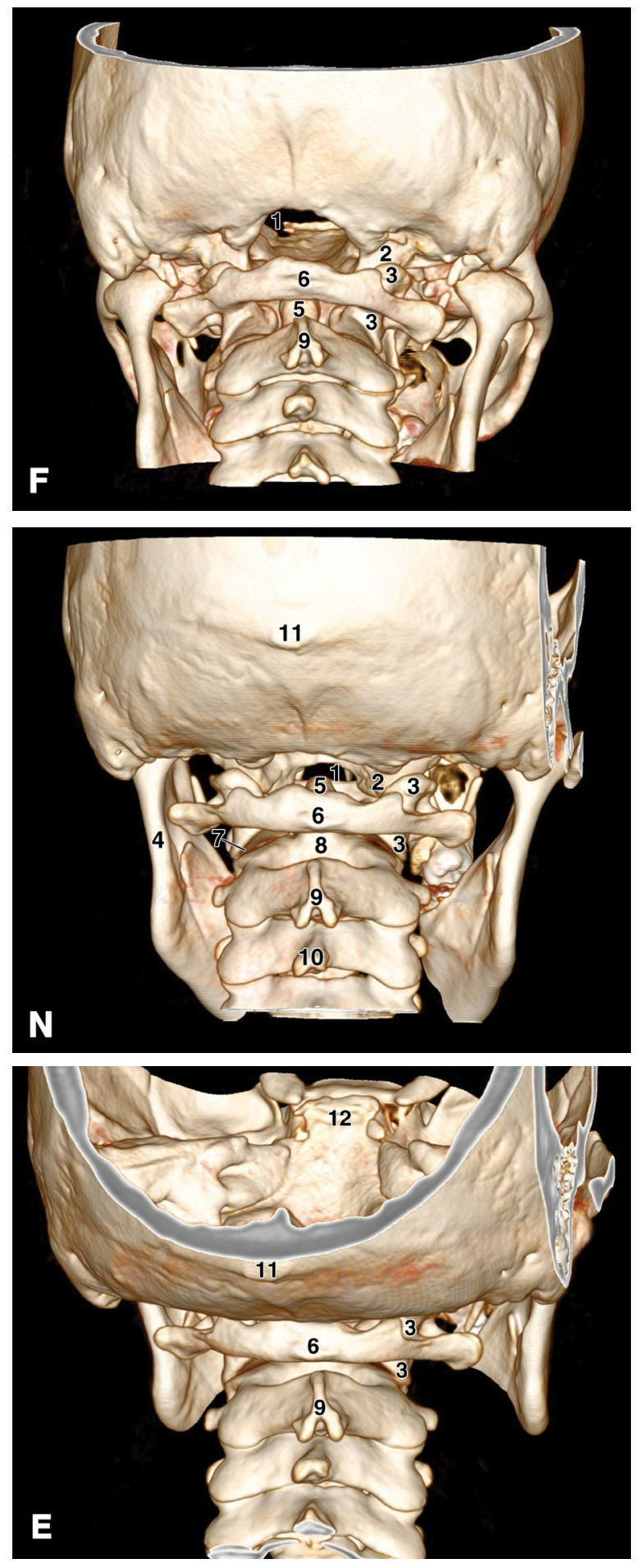

Figure 2. The posterior view of the craniovertebral junction in the three-dimensional multislice computed tomography images in flexion $(\mathbf{F})$, the neutral position $(\mathbf{N})$, and extension $(\mathbf{E}) ; 1$ - the foramen magnum; 2 - the right occipital condyle; 3 - the right lateral mass of the atlas; 4 - the left ramus of the mandible; 5 - the odontoid process (dens); 6 - the posterior tubercle of the atlas; 7 - the left lateral atlantoaxial joint; 8 - the posterior surface of the axis body; 9 - the spinous process of the axis; 10 - the spinous process of the third cervical vertebra; 11 the dorsum sellae.
The CVJ is designed to perform various movements, especially flexion, extension and rotation. The osseous components during the movements change their position and interrelationships (Figs. 2F, N, E). For that reason, we measured certain distances between those components (Fig. 3A, B) in the neutral position (Table 1), neck flexion (Table 2 ), and neck extension (Table 3 ) in our group of the 22 volunteers.

We shall present first the 14 mentioned parameters in the three positions, and then the angles in the same positions. The obtained congenital anomalies will be described as well.

\section{The parameters in flexion}

The parameter 1 was the shortest distance between the dens tip and the basion (Fig. 3B; Fig. 4F, N, E). It measured 1.50-8.20 mm (mean $3.95 \mathrm{~mm}$ ) in a neutral position (Table 1), and 1.20-7.80 mm (mean, $3.35 \mathrm{~mm}$ ) in flexion (Table 2). The difference between the neutral position and flexion ranged between $0.1 \mathrm{~mm}$ and $2.7 \mathrm{~mm}$ (mean, $0.84 \mathrm{~mm}$ ). It is obvious that the basion and the dens tip are closer together following flexion (Fig. 4F). The statistical analysis showed a significant difference ( $p<0.002$ ) between the neutral position and flexion.

The parameter 2 , i.e. the distance from the dens tip to the opisthion, was shorter (mean, $0.99 \mathrm{~mm}$ ) in most of the individuals, but without a statistical significance. As for the parameter 3, it represented the distance between the dens tip and the cranial border of the posterior atlas arch (Fig. 3B). It decreased in length by $1.10 \mathrm{~mm}$ on average following flexion in the majority of the volunteers. The parameter 4 , i.e. the distance from the base of the axis body to the opisthion (Fig. 3B), increased by $3.11 \mathrm{~mm}$ on average following flexion in most of the individuals. The parameter 5, that is, the sagittal diameter of the foramen magnum, had the same values (mean, $37.5 \mathrm{~mm}$ ) in both neutral position and flexion (Tables 1, 2).

The parameter 6 , which was the distance between the basion and the lower border of the axis arch (Fig. 3B), decreased by $1.66 \mathrm{~mm}$ on average in length in most individuals $(p<0.035)$. The parameter 7 , i.e. the distance between the basion and the most prominent point of the posterior atlas arch, was shorter (mean, $0.74 \mathrm{~mm}$ ) in the majority of the volunteers. This parameter showed a significant difference between flexion and extension. The same situation 

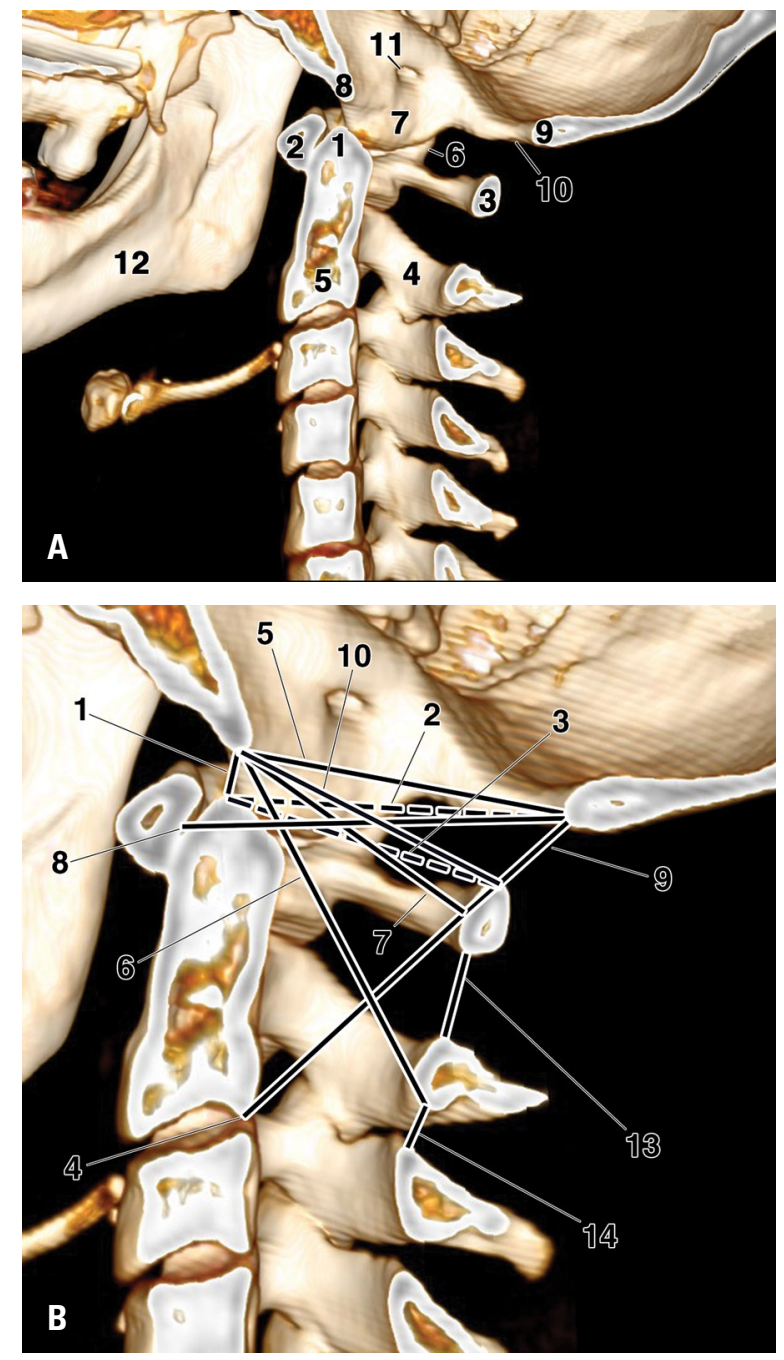

Figure 3. A. The mediosagittal three-dimensional multislice computed tomography section of the craniovertebral junction; 1 - the tip of the odontoid process (dens); 2 - the anterior, and 3 - the posterior arch of the atlas; 4 - the axis arch; 5 - the axis body; 6 - the right lateral mass; 7 - the right occipital condyle; 8 - the basion; 9 - the opisthion; 10 - the foramen magnum; 11 - the hypoglossal canal; 12 - the mandible; B. Some of the measured parameters of the craniovertebral junction presented in the same image as in Figure 4A. Note the distances between the dens tip and the basion (1), the opisthion (2), and the upper margin of the posterior arch of the atlas (3). Also note the distances between the dens base and the opisthion (4), the basion and the opisthion (5), the basion and the root of the axis spinous process (6), the basion and the middle of the posterior atlas arch (7), the middle point of the anterior atlas arch and the opisthion (8), the opisthion and the posterior atlas arch (9), the basion and the upper margin of the posterior atlas arch (10), the posterior atlas arch and the axis arch (13), and the spinous process of the axis and the third cervical vertebra (14). The distances 11 and 12 are described in the text.

was with the parameter $\mathbf{8}$, that is, with the distance from the opisthion to the anterior atlantal arch, i.e. its facet for the dens. It was longer (mean, $1.27 \mathrm{~mm}$ ) after flexion in most individuals.
Table 1. Distances [mm] within the craniovertebral junction in neutral position

\begin{tabular}{lcc}
\hline Parameters & $\begin{array}{c}\text { Min-max (mean) } \\
\text { 土 standard deviation }\end{array}$ & $\begin{array}{c}\text { 95\% confidence } \\
\text { interval }\end{array}$ \\
\hline 1 & $1.50-8.20(3.95) \pm 1.49$ & $3.28-4.61$ \\
2 & $30.00-44.10(36.84) \pm 3.40$ & $35.33-38.35$ \\
3 & $27.10-38.50(31.57) \pm 2.88$ & $30.29-32.84$ \\
4 & $41.40-57.50(49.70) \pm 4.97$ & $47.50-51.91$ \\
5 & $30.60-43.00(37.35) \pm 2.88$ & $36.07-38.62$ \\
6 & $40.20-57.80(48.10) \pm 3.74$ & $46.44-49.76$ \\
7 & $27.20-36.70(31.24) \pm 2.66$ & $30.06-32.41$ \\
8 & $38.10-51.50(44.31) \pm 3.57$ & $42.73-45.89$ \\
9 & $5.80-20.00(11.40) \pm 3.11$ & $10.01-12.78$ \\
10 & $28.50-40.50(33.57) \pm 2.99$ & $32.24-34.89$ \\
11 & $-4.10-6.30(1.68) \pm 2.19$ & $0.71-2.65$ \\
12 & $2.10-7.10(4.38) \pm 1.34$ & $3.79-4.98$ \\
13 & $3.50-11.70(7.40) \pm 2.39$ & $6.34-8.46$ \\
14 & $1.90-9.10(4.94) \pm 1.71$ & $4.18-5.69$ \\
\hline
\end{tabular}

Table 2. Distances [mm] within the craniovertebral junction in flexion

\begin{tabular}{lcc}
\hline Parameters & $\begin{array}{c}\text { Min-max (mean) } \\
\pm \text { standard deviation }\end{array}$ & $\begin{array}{c}\text { 95\% confidence } \\
\text { interval }\end{array}$ \\
\hline 1 & $1.20-7.80(3.35) \pm 1.51$ & $2.68-4.02$ \\
2 & $27.80-43.20(36.39) \pm 3.44$ & $34.86-37.91$ \\
3 & $26.90-37.20(31.19) \pm 2.68$ & $30.00-32.38$ \\
4 & $43.70-61.60(51.15) \pm 4.57$ & $49.13-53.18$ \\
5 & $30.60-43.00(37.35) \pm 2.88$ & $36.07-38.62$ \\
6 & $40.20-57.10(47.21) \pm 4.23$ & $45.33-49.08$ \\
7 & $26.70-37.50(31.06) \pm 2.78$ & $29.83-32.29$ \\
8 & $37.50-50.90(44.72) \pm 3.47$ & $43.18-46.26$ \\
9 & $7.50-23.00(13.20) \pm 3.36$ & $11.71-14.69$ \\
10 & $28.60-38.10(33.70) \pm 2.46$ & $32.61-34.78$ \\
11 & $-1.70-6.90(2.27) \pm 1.94$ & $1.41-3.13$ \\
12 & $1.20-7.50(4.02) \pm 1.81$ & $3.22-4.82$ \\
13 & $3.90-12.40(8.08) \pm 2.40$ & $7.02-9.15$ \\
14 & $1.80-8.70(5.35) \pm 1.85$ & $4.53-6.18$ \\
\hline
\end{tabular}

The parameter 9, which interconnects the opisthion and the cranial border of the posterior atlantal arch (Fig. 3B), increased in length (mean, $2.18 \mathrm{~mm}$ ) following flexion (Fig. 4F) $(p<0.0001)$. The parameter 10, which extends from the basion to the cranial margin of the posterior atlas arch, was slightly shorter (mean, $0.83 \mathrm{~mm}$ ) in one half of the volunteers, and slightly longer in those remaining $(0.82 \mathrm{~mm}$ each). 
Table 3. Distances [mm] within the craniovertebral junction in extension

\begin{tabular}{lcc}
\hline Parameters & $\begin{array}{c}\text { Min-max (mean) } \pm \\
\pm \text { standard deviation }\end{array}$ & $\begin{array}{c}\text { 95\% confidence } \\
\text { interval }\end{array}$ \\
\hline 1 & $3.10-11.00(6.44) \pm 2.05$ & $5.53-7.35$ \\
2 & $28.90-44.80(36.40) \pm 3.86$ & $34.69-38.11$ \\
3 & $26.80-38.00(31.41) \pm 2.93$ & $30.11-32.71$ \\
4 & $34.40-60.10(42.81) \pm 6.47$ & $39.94-45.68$ \\
5 & $30.60-43.00(37.35) \pm 2.88$ & $36.07-38.62$ \\
6 & $41.10-53.80(49.22) \pm 3.50$ & $47.67-50.77$ \\
7 & $27.80-39.20(32.91) \pm 3.02$ & $31.57-34.25$ \\
8 & $37.00-51.00(42.60) \pm 3.69$ & $40.97-44.24$ \\
9 & $1.00-27.10(7.12) \pm 5.42$ & $4.72-9.52$ \\
10 & $28.20-39.40(33.93) \pm 2.91$ & $32.64-35.22$ \\
11 & $-8.60-4.50(-0.15) \pm 2.69$ & $-1.34-1.04$ \\
12 & $2.60-10.10(6.13) \pm 1.94$ & $5.27-6.99$ \\
13 & $1.30-13.60(4.96) \pm 2.82$ & $3.72-6.21$ \\
14 & $0.90-7.00(3.31) \pm 1.59$ & $2.61-4.02$ \\
\hline
\end{tabular}

The parameter 11 presented a horizontal distance from the basion to the longitudinal axis of the dens (not presented in Fig. 3B). In the volunteers with a positive value of that parameter (Fig. $4 \mathrm{~N}$ ), the dens tip was positioned not only inferior but also posterior to the basion (in 72.7\%) at a mean distance of $2.65 \mathrm{~mm}$. Following flexion, it was shorter (mean, $1.07 \mathrm{~mm}$ ) than in the neutral position in one half of the volunteers, but it was slightly longer (mean, $0.99 \mathrm{~mm}$ ) or unchanged in the remaining subjects. The dens tip was rarely seen inferior to and at the basion level $(18.2 \%)$. In the individuals with a negative value $(9.1 \%$ ) of this parameter (Tables 1,2 ), the dens tip was located not only inferior but also slightly anterior to the basion level. Nevertheless, there was a significant statistical difference between the parameter 11 values in the neutral position and flexion ( $p<0.047)$.

The parameter 12 (not presented in Fig. 3B) is a vertical diameter on the dens axis, which extends from its intersection with the parameter 11 line to the tip of the dens. It was shorter (mean, 1.35 $\mathrm{mm}$ ) following flexion. The parameter 13 was the distance between the posterior atlas arch and the axis arch (Fig. 3B). Similarly, the parameter 14 represented the distance between the arches of the axis and the third cervical vertebra (Fig. 3B). The parameter 13 was longer (mean, $1.32 \mathrm{~mm}$ ) in flexion, as was the parameter 14 (mean, $1.44 \mathrm{~mm}$ ) in the majority of the volunteers
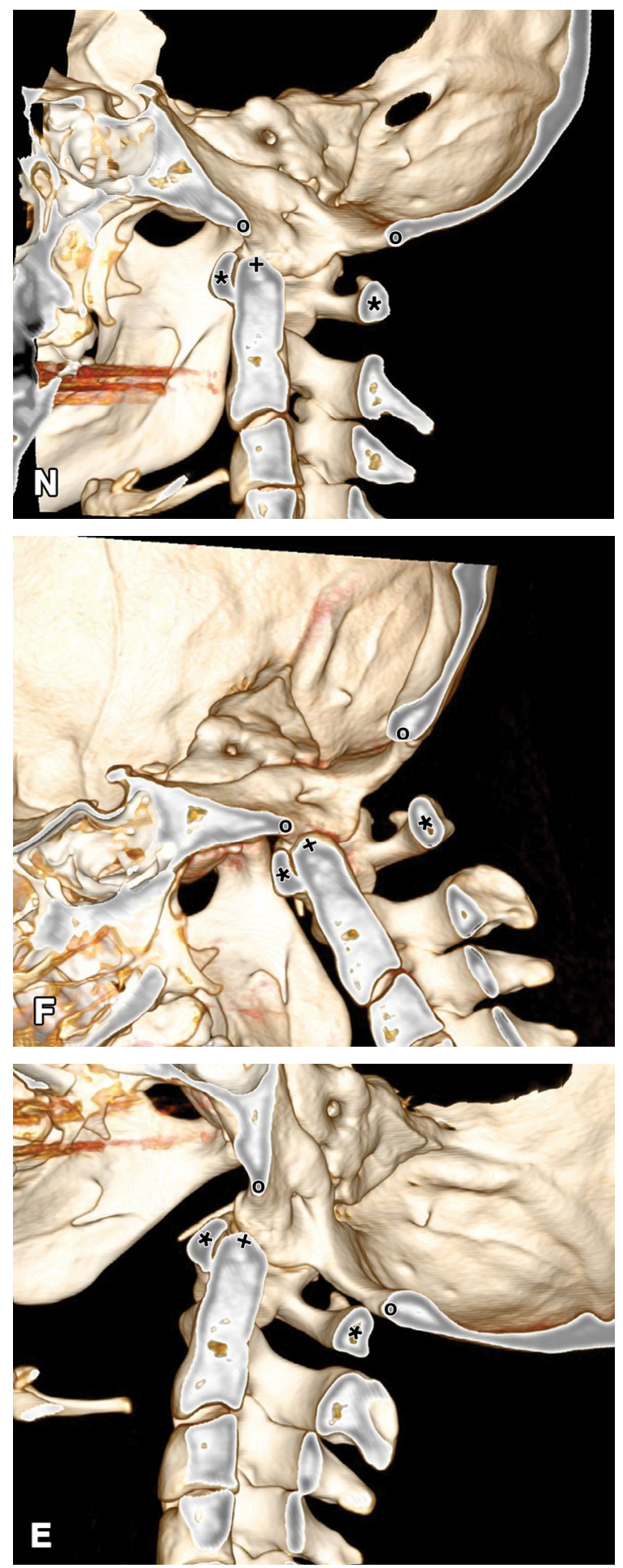

Figure 4. The sagittal three-dimensional multislice computed tomography section of the craniovertebral junction in the neutral position $(\mathbf{N})$, flexion $(\mathbf{F})$ and extension $(\mathbf{E})$. Note the position of the dens tip $(+)$, the anterior and the posterior arch of the atlas $\left({ }^{*}\right)$, and the basion and the opisthion (0).

\section{The parameters in extension}

The parameter 1, after comparing the extension values to the data in the neutral position, increased in 
length by $2.81 \mathrm{~mm}$ on average $(\mathrm{p}<0.0001)$. Obviously, the dens tip is more distant to the basion following extension (Fig. 4E). The parameter 2 presented either a decrease (mean, $1.44 \mathrm{~mm}$ ) or an increase (mean, $0.81 \mathrm{~mm}$ ) in length. The parameter 3 showed an increase (mean, $0.63 \mathrm{~mm}$ ), and less frequently a decrease (mean, $1.30 \mathrm{~mm}$ ) in length. The parameter 4 presented a great decrease in length (mean, $8.16 \mathrm{~mm}$ ) ( $p<0.0001)$. The parameter 5, i.e. the sagittal diameter of the foramen magnum, was unchanged.

The parameter 6 was increased (mean, $2.40 \mathrm{~mm}$ ) following extension ( $p<0.035)$. Parameter 7 also increased in length (mean, $1.77 \mathrm{~mm})(p<0.0001)$. The parameter 8 was longer (mean, $3.58 \mathrm{~mm}$ ), and less frequently shorter (mean, $1.6 \mathrm{~mm}$ ). The parameter 9 showed a great decrease in length (mean, $5.39 \mathrm{~mm}$ ) ( $p<0.0001)$, whereas the parameter 10 increased in length (mean, $1.14 \mathrm{~mm}$ ).

The parameter 11 was shorter (mean, $2.73 \mathrm{~mm}$ ) compared to the neutral position ( $p<0.0001$ ). In these cases, the dens tip, which was inferiorly positioned, moved anteriorly toward the basion in $45.5 \%$ of the subjects, or took a position at the level of the basion (22.7\%). The parameter 12 was longer (mean, $2.01 \mathrm{~mm})$ in all subjects $(p<0.0001)$. The parameter 13 was shorter (mean, $3.09 \mathrm{~mm}$ ). The parameter 14 decreased in length as well (mean, $1.78 \mathrm{~mm}$ ).

\section{The angles in flexion and extension}

As regards the measured angles, the alpha $(\alpha)$ angle was drawn starting from the opisthion. Its upper limb represented the midsagittal diameter (the parameter 5) of the foramen magnum, whilst its lower limb passed through the tip of the dens (like the parameter 2). This angle (Table 4) decreased in flexion by $1^{\circ}$ to $3^{\circ}$ (mean, $\left.1.59^{\circ}\right)$. In extension, however, it increased by $1^{\circ}$ to $8^{\circ}$ (mean, $3.18^{\circ}$ ). The statistically significant difference was noticed in both instances ( $p<0.001$ each).

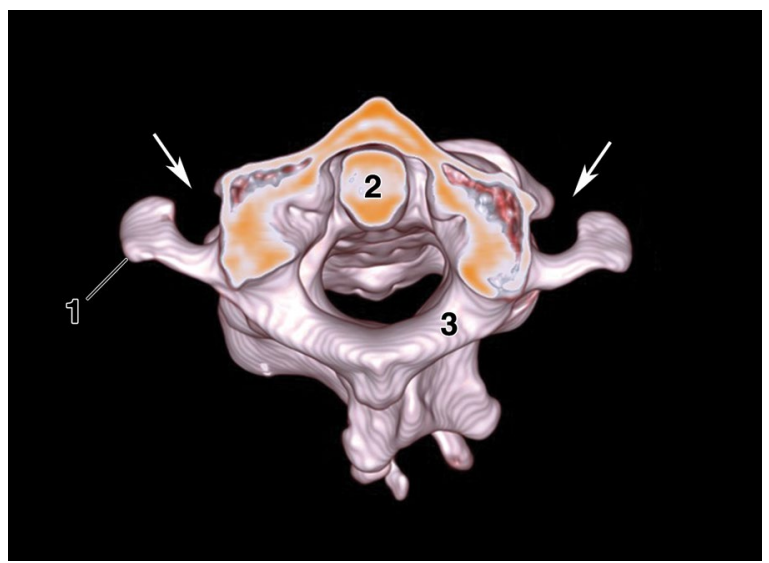

Figure 5. A unilateral and bilateral unclosed foramen transversarium (arrows) of the atlas in the superior view; 1 - the left transverse process; 2 - the dens; 3 - the posterior atlantal arch.

The beta $(\beta)$ angle was drawn from the caudal and dorsal point of the axis body, i.e. exactly where parameter 6 started (Fig. 3B). The anterior limb passed along the posterior aspect of the axis body, whilst the posterior limb coursed through the opisthion (like the mentioned parameter 6$)$. This angle was shorter in flexion by $1^{\circ}$ to $11^{\circ}$ (mean, $\left.3.36^{\circ}\right)$. On the other hand, the value of the angle increased in extension by $1^{\circ}$ to $24^{\circ}$ (mean, $7.10^{\circ}$ ). The statistically significant difference was observed in both cases ( $p<0.001$ each).

\section{Congenital anomalies}

Of the 22 volunteers, we found incidentally certain anomalies in 4 of them. Most often (13.6\%) an anteriorly unclosed foramen transversarium of the atlas was observed, in 2 individuals unilaterally and in 1 on both sides (Fig. 5). This dehiscence measured from $5.1 \mathrm{~mm}$ to $11.0 \mathrm{~mm}$ (mean, $8.0 \mathrm{~mm}$ ) in diameter. The longest transverse diameter of these atlases, i.e. the distance between the tips of the right and left transverse processes, measured between $76.7 \mathrm{~mm}$ and $87.9 \mathrm{~mm}$ (mean, $84.1 \mathrm{~mm}$ ).

Table 4. The values of the angles $\left[{ }^{0}\right]$ in three cervical spine positions

\begin{tabular}{lccc}
\hline Position & Angles & Min-max (mean) \pm standard deviation & 95\% confindence interval: lower/upper bound \\
\hline Neutral & $\alpha$ & $1.0-9.0(6.09) \pm 2.00$ & $5.21-6.98$ \\
& $\beta$ & $29.0-47.0(37.32) \pm 4.24$ & $35.44-39.20$ \\
Flexion & $\alpha$ & $2.0-9.0(5.00) \pm 1.85$ & $4.18-5.82$ \\
& $\beta$ & $27.0-41.0(33.95) \pm 3.96$ & $32.20-35.71$ \\
Extension & $\alpha$ & $1.0-15.0(9.32) \pm 3.15$ & $7.92-10.72$ \\
& $\beta$ & $31.0-51.0(42.91) \pm 5.76$ & $40.35-45.46$ \\
\hline
\end{tabular}




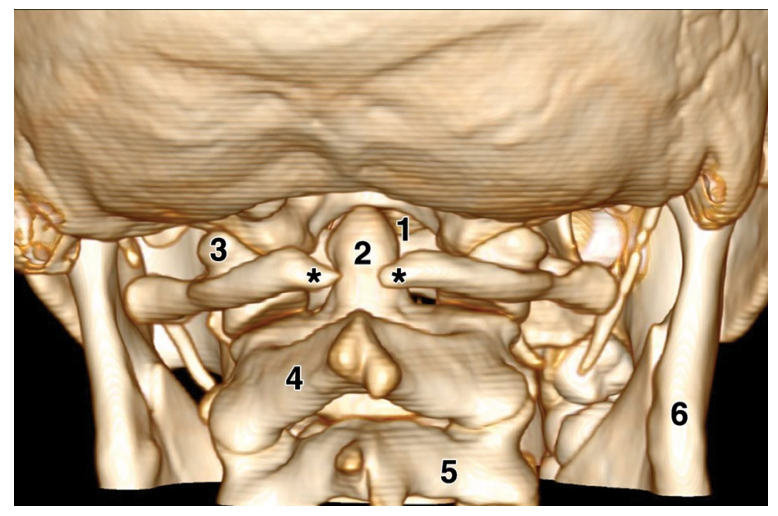

Figure 6. Posterior view of the skull and the cervical spine to show a partial agenesis of the posterior atlas arch (between the two asterisks); 1 - the foramen magnum; 2 - the odontoid process (dens); 3 - the lateral mass of the atlas; 4 - the arch of the axis; 5 - the third cervical vertebra; 6 - the ramus of the mandible.

In $1(4.5 \%)$ volunteer a partial agenesis of the posterior arch of the atlas was noticed (Fig. 6). This defect, which measured $5.2 \mathrm{~mm}$, was located in the middle part of that arch. The radiologic examination of the defect following flexion and extension showed no CVJ instability.

\section{DISCUSSION}

We paid a special attention to the mechanism of the mentioned movements, that is, to the changes of the CVJ bones relationships following flexion and extension.

\section{The CVJ in flexion}

Due to a posterior gliding of the occipital condyles along the superior articular facets of the atlas during flexion, the anterior part of the occiput moves inferiorly (Fig. 4F), so that the tip of the dens gets closer to the basion inferiorly (the parameter 1) but also posteriorly (the parameter 11). The foramen magnum and the opisthion become displaced superiorly. The distance of the dens tip to the opisthion (the parameter 2) slightly decreases in length, as does the distance to the posterior atlas arch (the parameter 3). The distance is usually also shorter from the latter arch to the basion (the parameters 7 and 10), as well as to the axis arch (the parameter 6).

The posterior atlas arch becomes distant from the opisthion (the parameter 9). Due to an anterior (ventral) bending of the cervical spine, the anterior part of the intervertebral disks is narrowed, whereas the distances among the C1, C2 and C3 arches (the parameters 13 and 14) are usually longer in length
(Figs. 2F, 4F). The $\mathrm{C} 2$ arch moves not only slightly superiorly but also slightly anteriorly (ventrally) (Figs. 4N, 4F). The dens-atlas distance within the median atlantoaxial joint is slightly shorter. In contrast, the distance between the articular facets of the $\mathrm{C} 1$ and C2 vertebrae is longer (Fig. 2F). Finally, as regards the two measured angles, both the $\alpha$ and $\beta$ angles are smaller in flexion.

The maximum flexion of the cervical spine is about $40^{\circ}$ [25]. According to certain authors [19, 22, 29, $34]$, the range of flexion in the $\mathrm{Oc}-\mathrm{C} 1$ joint averages $23.0-27.1^{\circ}$, lateral bending is from $3.4^{\circ}$ to $5.5^{\circ}$, and axial rotation varies between $2.4^{\circ}$ and $7.2^{\circ}$. As regards the $\mathrm{C} 1-\mathrm{C} 2$ joints, the mean value of flexion is $10.1^{\circ}$. Lateral bending reaches up to $6.7^{\circ}$ on average, whilst the axial rotation averages $23.3-38.9^{\circ}$ per side.

\section{The CVJ in extension}

Two main changes can be seen in the extension: an inferior movement of the posterior part of the occiput, as well as a posterior bending of the cervical spine (Fig. 4E).

Due to the former, the occiput is very close to the posterior atlas arch (the parameter 9) (Figs. 3B, 4E). On the contrary, there is a longer distance between the basion and the anterior atlantal arch and the tip of the dens (the parameter 1). A longer distance is also present between the basion, on the one hand, and the axis arch (the parameter 6) and the posterior atlas arch (the parameters 7 and 10), on the other hand. The distance from the dens tip to the opisthion (the parameter 2 ) is either longer or shorter, as is the distance to the posterior atlas arch (the parameter 3 ). The distance of the axis base to the opisthion (the parameter 4) is shorter in length. It is usually the same thing with the distance between the anterior atlantal arch and the opisthion (the parameter 8).

Due to the posterior (dorsal) bending of the cervical spine, the distances among the $\mathrm{C} 1-\mathrm{C} 3$ arches (the parameters 13 and 14) are significantly shorter, as are the distances between the articular facets of the cervical vertebrae (Fig. 2E). The anterior parts of the intervertebral disks are larger in height (Figs. 2E, 4E). Certain vertebral arches move slightly posteriorly, i.e. dorsally (compare Figs. $4 \mathrm{~N}$ and $4 \mathrm{E}$ ).

Finally, both the $\alpha$ and $\beta$ angles are larger in extension, what showed a highly significant difference ( $p<0.001$ each).

According to some authors [25] the maximum extension of the cervical spine, compared to the neutral position, is about $20^{\circ}$. According to other reports 
$[22,34]$, extension in the Oc-C1 joint is between $24.5^{\circ}$ and $24.9^{\circ}$ on average, while in the $\mathrm{C} 1-\mathrm{C} 2$ joints it averages $22.4^{\circ}$.

The variability of the same parameter in our volunteers in the same neck position, either flexion or extension, can occur due to two reasons. Firstly, because of an erroneous measuring of some parameters. In order to diminish the possible errors, two independent radiologists performed the measurements, and their results were virtually identical. Secondly, some individual variations of certain parameters in the CVJ biomechanics cannot be excluded.

\section{Congenital anomalies}

We did not find any anomaly of the occipital bones in our volunteers. On the other hand, we noticed, firstly, three unclosed foramina transversaria of the atlas and, secondly, a partial agenesis of its posterior arch in one subject.

The former anomaly was reported several times $[1,18]$, whereas the absence of that foramen was noticed extremely rarely [35]. The incidence of the mentioned incomplete foramen is between $2.0 \%$ and $10.2 \%$, which is slightly less than in our group of the volunteers (13.6\%). This defect is usually located on one side and rarely on both sides of the atlas, as was revealed in one of our volunteers (Fig. 5).

This unclosed foramen is probably a result of a disorder of the lateral secondary ossification centre of the atlas, but an evolutionary cause cannot be excluded [1, 27]. As regards the other cervical vertebrae, including the axis, an occasional defect of their transverse processes and foramina was reported as a consequence of the congenital absence of the costal element $[13,36]$. In addition, the latter defect can also be acquired, in which case it is due to the compression by a tortuous vertebral artery.

We also found a partial agenesis of the posterior arch of the atlas in one volunteer. A partial failure of the lateral primary centre and the two posterior paramedian secondary centres are most likely the basis of this defect $[26,27,33]$. Other authors reported various anomalies affecting the posterior arch, and very rarely the lateral mass or the anterior arch (0.09$0.4 \%)[4,5,7,16,27,28,30,33]$. Some anomalies may simulate certain atlas fractures $[3,15]$.

In our volunteer, a middle defect of the posterior arch was observed. There is sometimes a combination of the anterior-posterior arch anomalies, which is known as a split or bipartite atlas [14]. We found such a combination in our previous patient with a double pituitary gland [23]. Some of the mentioned anomalies can cause the atlanto-occipital instability $[27,28,33]$.

As regards the axis, we did not observe any anomaly in the present study, but we described a duplication of the odontoid process and the axis body in the mentioned patient [23]. The same anomaly was noticed by some other authors as well [10, 32].

\section{General discussion}

Although most of the total angular mobility of the cervical spine is expressed at the level of the C4/ C5 and C5/C6 vertebrae [25, 34], it was observed that the CVJ is the most mobile part of the vertebral column $[22,34]$. Thus, most of the cranial flexion, extension and rotation are performed at the CVJ [19]. For this reason, many authors examined the movements of the CVJ, which are enabled by the CVJ bones, that is, the occiput, atlas and axis, connected by certain joints: the atlanto-occipital (Oc-C1), and the median and lateral atlantoaxial joints (C1-C2) $[19,22,34]$.

The bones are interconnected by the capsular ligaments, and by the corresponding syndesmoses. The CVJ joints enable flexion, extension, lateral bending, and rotation of the head and neck. Whilst the $\mathrm{C} 1-\mathrm{C} 2$ joints are essential in head rotation, the right and left $\mathrm{Oc}-\mathrm{C} 1$ joints are crucial in flexion and extension. The mentioned syndesmoses stabilise the CVJ complex, but also restrict hyperflexion, hyperextension and hyper-rotation, thus protecting the joints themselves, but also the nearby valuable vascular elements and vital neural structures [19, 22, 34]. The excessive movements within the Oc-C1 joints are limited by the alar ligaments, the transverse ligament of the atlas and, perhaps, by the tectorial membrane $[22,34]$.

Some of the parameters, or the ratio of the corresponding diameters, in a neutral position are important in the evaluation of the interrelationships of the CVJ bones in normal and pathologic situations $[11,22]$. Thus, the diameters 4 and 6 normally do not intersect the atlas or the axis (Fig. 3B). The value of the horizontal distance between the basion and a line along the posterior aspect of the axis body (which was not measured in our study) normally does not exceed $12 \mathrm{~mm}$ anteriorly and $4 \mathrm{~mm}$ posteriorly. Finally, the so-called Powers' ratio, which is the relationship 
between parameters 7 and 8, is normally less than 1 . Whereas the ratio remains the same in flexion and extension, some of the mentioned parameters do change in those two positions.

As already mentioned, certain congenital anomalies may appear within the CVJ. Two types of them were found in our study as well. They did not cause craniocervical instability.

\section{CONCLUSIONS}

Our study presented a detailed examination of 14 parameters and two angles in 22 volunteers. The measured diameters decreased or increased, respectively, in neck flexion and extension compared to the neutral position. The two angles also changed their values following the mentioned movements. Several congenital anomalies were observed as well. The obtained data can be of a certain clinical significance, especially in the orthopaedics, rheumatology, neurology and neurosurgery.

\section{Acknowledgements}

This work was supported by grant No. 175061 from the Ministry of Science, Serbia. We are very grateful to Ms. Elza Holt for reviewing the English text of our manuscript

\section{REFERENCES}

1. Billmann F, Le Minor JM. Transverse foramen of the atlas (C1) anteriorly unclosed: a misknown human variant and its evolutionary significance. Spine. 2009; 34(12): E422-E426, doi: 10.1097/BRS.0b013e3181a2e07e, indexed in Pubmed: 19454993.

2. Bilston LE, Thibault LE. The mechanical properties of the human cervical spinal cord in vitro. Ann Biomed Eng. 1996; 24(1): 67-74, doi: 10.1007/bf02770996, indexed in Pubmed: 8669719.

3. Caro AF, Prieto PM, Berciano F. Congenital defect of the atlas and axis. A cause of misdiagnose when evaluating an acute neck trauma. Am J Emerg Med. 2008; 26: e1-840.e2.

4. Chau AM, Wong JHY, Mobbs RJ. Cervical myelopathy associated with congenital $\mathrm{C} 2 / 3$ canal stenosis and deficiencies of the posterior arch of the atlas and laminae of the axis: case report and review of the literature. Spine. 2009; 34(24): E886-E891, doi: 10.1097/BRS.0b013e3181 b64f0a, indexed in Pubmed: 19910758.

5. Currarino G, Rollins N, Diehl JT. Congenital defects of the posterior arch of the atlas: a report of seven cases including an affected mother and son. AJNR Am J Neuroradiol. 1994; 15(2): 249-254, doi: 10.1179/bjo.22.1.71, indexed in Pubmed: 8192068.

6. D'Andrea K, Dreyer J, Fahim DK. Utility of Preoperative Magnetic Resonance Imaging Coregistered with Intraop- erative Computed Tomographic Scan for the Resection of Complex Tumors of the Spine. World Neurosurg. 2015; 84(6): 1804-1815, doi: 10.1016/j.wneu.2015.07.072, indexed in Pubmed: 26278864.

7. Elmalky MM, Elsayed S, Arealis G, et al. Congenital C1 arch deficiency: Grand Round presentation. Eur Spine J. 2013; 22(6): 1223-1226, doi: 10.1007/s00586-013-2682-z, indexed in Pubmed: 23479026.

8. Endo $K$, Suzuki $H$, Nishimura $H$, et al. Kinematic analysis of the cervical cord and cervical canal by dynamic neck motion. Asian Spine J. 2014; 8(6): 747-752, doi: 10.4184/ asj.2014.8.6.747, indexed in Pubmed: 25558316.

9. Fiford RJ, Bilston LE. The mechanical properties of rat spinal cord in vitro. J Biomech. 2005; 38(7): 1509-1515, doi: 10.1016/j.jbiomech.2004.07.009, indexed in Pubmed: 15922762.

10. Garant M, Oudjhane K, Sinsky A, et al. Duplicated odontoid process: plain radiographic and CT appearance of a rare congenital anomaly of the cervical spine. AJNR Am J Neuroradiol. 1997; 18(9): 1719-1720, doi: 10.2106/00004623-198062080-00021, indexed in Pubmed: 9367321.

11. Garrett M, Consiglieri G, Kakarla UK, et al. Occipitoatlantal dislocation. Neurosurgery. 2010; 66(3 Suppl): 48-55, doi: 10.1227/01.NEU.0000365802.02410.C5, indexed in Pubmed: 20173527.

12. Gerigk L, Bostel T, Hegewald A, et al. Dynamic magnetic resonance imaging of the cervical spine with high-resolution 3-dimensional T2-imaging. Clin Neuroradiol. 2012; 22(1): 93-99, doi: 10.1007/s00062-011-0121-2, indexed in Pubmed: 22193978.

13. Gomez MA, Damie F, Besson M, et al. [Congenital absence of a cervical spine pedicle: misdiagnosis in a context of trauma]. Rev Chir Orthop Reparatrice Appar Mot. 2003; 89(8): 738-741, doi: 10.4103/0028-3886.173669, indexed in Pubmed: 14726842.

14. Hu Y, Ma W, Xu R. Transoral osteosynthesis C1 as a function-preserving option in the treatment of bipartite atlas deformity: a case report. Spine. 2009; 34(11): E418-E421, doi: 10.1097/BRS.0b013e3181a0ff2f, indexed in Pubmed: 19444056.

15. Kakarla UK, Chang SW, Theodore N, et al. Atlas fractures. Neurosurgery. 2010; 66(3 Suppl): 60-67, doi: 10.1227/01.NEU.0000366108.02499.8F, indexed in Pubmed: 20173529.

16. Klimo P, Blumenthal DT, Couldwell WT. Congenital partial aplasia of the posterior arch of the atlas causing myelopathy: case report and review of the literature. Spine. 2003; 28(12): E224-E228, doi: $10.1097 / 01 . B R S .0000065492 .85852 . A 9$, indexed in Pubmed: 12811285.

17. Lao Lf, Zhong Gb, Li Qy, et al. Kinetic magnetic resonance imaging analysis of spinal degeneration: a systematic review. Orthop Surg. 2014; 6(4): 294-299, doi: 10.1111/ os.12137, indexed in Pubmed: 25430713.

18. Le Minor JM, Koritke JG. [Associations among nonmetric features of the atlas in the human species]. Arch Anat Histol Embryol. 1991; 74: 11-26, indexed in Pubmed: 1366344. 
19. Lopez AJ, Scheer JK, Leibl KE, et al. Anatomy and biomechanics of the craniovertebral junction. Neurosurg Focus. 2015; 38(4): E2, doi: 10.3171/2015.1.FOCUS14807, indexed in Pubmed: 25828496.

20. Lord EL, Alobaidan R, Takahashi S, et al. Kinetic magnetic resonance imaging of the cervical spine: a review of the literature. Global Spine J. 2014; 4(2): 121-128, doi: 10.1055/ s-0034-1375563, indexed in Pubmed: 25054099.

21. Magu S, Singh D, Yadav RK, et al. Evaluation of Traumatic Spine by Magnetic Resonance Imaging and Correlation with Neurological Recovery. Asian Spine J. 2015; 9(5): 748-756, doi: 10.4184/asj.2015.9.5.748, indexed in Pubmed: 26435794.

22. Martin MD, Bruner HJ, Maiman DJ. Anatomic and biomechanical considerations of the craniovertebral junction. Neurosurgery. 2010; 66(3 Suppl): 2-6, doi: 10.1227/01.NEU.0000365830.10052.87, indexed in Pubmed: 20173523.

23. Milić I, Samardžić M, Djorićl, et al. Craniovertebral anomalies associated with pituitary gland duplication. Folia Morphol. 2015; 74(4): 524-531, doi: 10.5603/FM.2015.0118, indexed in Pubmed: 26620517.

24. Morishita Y, Falakassa J, Naito M, et al. The kinematic relationships of the upper cervical spine. Spine. 2009; 34(24): 2642-2645, doi: 10.1097/BRS.0b013e3181b435e4, indexed in Pubmed: 19910767.

25. Morishita $Y$, Hymanson H, Miyazaki M, et al. Review article: Kinematic evaluation of the spine: A kinetic magnetic resonance imaging study. J Orthopaedic Surg. 2008; 16(3): 348-350, doi: 10.1177/230949900801600316.

26. O'Rahilly R, Müller F, Meyer DB. The human vertebral column at the end of the embryonic period proper. 2 . The occipitocervical region. J Anat. 1983; 136(Pt 1): 181-195, doi: 10.1002/ aja.1001890204, indexed in Pubmed: 6833119.

27. Pang D, Thompson DNP. Embryology and bony malformations of the craniovertebral junction. Childs Nerv Syst. 2011; 27(4): 523-564, doi: 10.1007/s00381-010-1358-9, indexed in Pubmed: 21193993.

28. Pasku D, Katonis P, Karantanas A, et al. Congenital posterior atlas defect associated with anterior rachischisis and early cervical degenerative disc disease: a case study and review of the literature. Acta Orthop Belg. 2007; 73(2): 282-285, doi: 10.4103/0028-3886.136974, indexed in Pubmed: 17515248.
29. Pfirrmann CW, Binkert CA, Zanetti M, et al. Functional MR imaging of the craniocervical junction. Correlation with alar ligaments and occipito-atlantoaxial joint morphology: a study in 50 asymptomatic subjects. Schweiz Med Wochenschr. 2000; 130(18): 645-651, doi: 10.1148/radiology.218.1.r01ja36133, indexed in Pubmed: 10846756.

30. Sabuncuoglu H, Ozdogan S, Karadag D, et al. Congenital hypoplasia of the posterior arch of the atlas: case report and extensive review of the literature. Turk Neurosurg. 2011; 21(1): 97-103, doi: 10.5137/1019-5149.jtn.255909.2, indexed in Pubmed: 21294100.

31. Schlamann M, Reischke L, Klassen D, et al. Dynamic magnetic resonance imaging of the cervical spine using the NeuroSwing System. Spine. 2007; 32(21): 2398-2401, doi: 10.1097/BRS.0b013e31815588ed, indexed in Pubmed: 17906585.

32. Shen W, Cui J, Chen J, et al. Partial midfacial duplication. J Craniofac Surg. 2013; 24(3): 934-936, doi: 10.1097/SCS.0b013e31828606a1, indexed in Pubmed: 23714914.

33. Smoker WR. Craniovertebral junction: normal anatomy, craniometry, and congenital anomalies. Radiographics. 1994; 14(2): 255-277, doi: 10.1148/radiographics.14.2.8190952, indexed in Pubmed: 8190952.

34. Steinmetz MP, Mroz TE, Benzel EC. Craniovertebral junction: biomechanical considerations. Neurosurgery. 2010; 66(3 Suppl): 7-12, doi: 10.1227/01.NEU.0000366109.85796.42, indexed in Pubmed: 20173531.

35. Vasudeva N, Kumar R. Absence of foramen transversarium in the human atlas vertebra: a case report. Acta Anat (Basel). 1995; 152(3): 230-233, doi: 10.1159/000147702, indexed in Pubmed: 7572033.

36. Wiener MD, Martinez S, Forsberg DA. Congenital absence of a cervical spine pedicle: clinical and radiologic findings. AJR Am J Roentgenol. 1990; 155(5): 1037-1041, doi: 10.2214/ajr.155.5.2120932, indexed in Pubmed: 2120932.

37. Zhang $H$, Bai J. Development and validation of a finite element model of the occipito-atlantoaxial complex under physiologic loads. Spine. 2007; 32(9): 968-974, doi: 10.1097/01.brs.0000261036.04919.91, indexed in Pubmed: 17450071. 